\title{
Exploring the Mediating Role of The Balance Use of the Performance Measurement System on the Relationship Between Intellectual Capital and Firm Performance
}

\author{
Hoang Thanh Nhon \\ Van Lang University, Ho Chi Minh City, Vietnam \\ E-mail: nhon.ht@vlu.edu.vn
}

Received: October 8, 2020 Accepted: August 8, $2021 \quad$ Published: August 9, 2021

doi:10.5296/bms.v12i2.18917ＵRL: https://doi.org/10.5296/bms.v12i2.18917

\begin{abstract}
The purpose of this paper is to empirically explore how the balance use of performance measurement systems mediate the effects of intellectual capital dimensions including human, organizational and social capital on firm performance. The data were collected from a survey of 448 Vietnamese managers of Information and Communication Technology Sector and proposed hypotheses were tested by using partial least squares regression and a structural modeling technique which is appropriate for highly complex predictive models. Findings from hypotheses tests indicated that firms with higher level of intellectual capital dimensions place a premium on the balance use of performance measurement systems in a diagnostic and interactive style. Furthermore, the result also provides some evidences that Intellectual capital dimensions effect indirectly on firm performance through performance measurement systems.
\end{abstract}

Keywords: intellectual capital, human capital, organizational capital, social capital, the balance use of performance measurement systems

\section{Introduction}

For many years, while in human, organizational and social capital, became very important intangible resources (Davison, 2014) in determining a firm performance (FB), there are still growing debates on the supporting role of management control systems, one of the prime dimensions of the strategic management, within the intellectual capital (IC) setting (Widener, 2006; Cleary, 2015; Toorchi et al., 2015; Novas et al., 2017). These debates have made a gap 
in the literature that academic researchers are trying to fill up. (Asiaei et al, 2018). In addition, academic researchers try to clarify on how management control systems are favorably involved in capturing, measuring, and managing firm's IC (Asiaei et al, 2018). In fact, an effective management control system may support and facilitate IC development to fully realize the potential intangibles (Cuozzo et al, 2017). However, there are increasing concerns that current management control systems fail to support distinctive features of the firm (Asiaei et al, 2018). Therefore, it has been argued that one of the barriers to firm's success is attributed to its inability to develop a robust management control system (Asiaei et al, 2018). This issue becomes critical in today's knowledge era where executives require timely and relevant information to raise the successfulness of their decision making (Asiaei et al, 2018).

Performance measurement (PM) system, one of the most important dimensions of management control systems, is a system which has developed in parallel with the evolution of the intangible resources (Asiaei et al, 2018). According to academic researchers, the balance use of PM system positively leverages and facilitates the management of strategic resources (Bontis et al, 2018). In this regard, PM are perceived as an important tool to support firm for pursuit of the competitive advantages.

The success of the balance use of PM system is the one assisting executives track firm performance to achieve strategic goals. In fact, IC and its elements are important factors for firm value creation, the framework and nature of PM systems must be innovative enough in order to increase the contributions of those intangible resources (Bontis et al, 2018).

\section{Theoretical Background and Hypotheses}

\subsection{Intellectual Capital Dimensions}

The growing extent literature in the field of IC cover a classification of the intangible resources (Cuozzo et al, 2017). The most common dimensions or categories are suggested to be human, organizational, and social capital (Cuozzo et al., 2017) which has become a cornerstone for the development and measurement of IC.

The first and the most important intangible capital dimension is human capital (HC) (Nhon et al, 2018). HC relates to the competence of employees, which includes the knowledge, skills, experiences, and abilities (Felício et al., 2014). HC is accumulated from idiosyncratic learning processes referring to core-competencies and skills that individuals gain in the working environment and is highly transferable across the firm.

The second intellectual capital dimension mentioned is organizational capital (OC) referring to the institutionalized knowledge and codified experiences preserved in and utilized through databases, patents, manuals, structures, systems, and processes (Tong, C., Tak, W. I. W., \& Wong, A., 2015; Vuong et al., 2014). Other researchers define organizational capital as the set of rules, norms, routines and organizational culture helping to the development of organizational competence (Mention, A. L., \& Bontis, 2013). However, Subramanian and Youndt (2005) argue that OC fits better in explaining that it is left behind in the firm when 
employees go home, owned by the firm and a strategic asset (Lev, B., \& Zambon, 2003; Tong, C., Tak, W. I. W., \& Wong,A., 2015). Hence, accumulating, codifying and storing information and knowledges are very important for the firm. Moreover, it enables efficient communication within an organization to facilitate knowledge-related activities and eventually contributes to values and profits. Therefore, if it is incorporated into their competitive intelligence, the overall business strategy will not only creatively transform the way they gather, produce and transmit knowledge, but also gain a better position to generate higher quality, lower costs and deeper insight leading to better performance

The last IC component is social capital (SC). SC can be understood as a set of informal norms, values, and commons to the members of a specific group that allows the cooperation and communication among them (Whiteley, 2015). In other words, it is regarded as the knowledge embedded within, available through, and used by interactions among individuals and their networks of interrelationships (Whiteley, 2015). Therefore, at macro-level, it is considered as a key-element for human, social and economic development. At micro-level, social capital involves not only knowledge and information exchanges among employees within the firm but also extended to the association with external parties related to the firms such as customers, suppliers, and partners.

A firm with rich SC may advance the quality of teamwork and increase communication smoothly among team members. SC is not owned by individuals or organizations. It assumes an interconnecting role for IC dimensions leveraging knowledge in groups and network of people important to the firms. In the structural dimension of SC focuses on the presence of relationships between the actors which relates the configuration or morphology of the network described by the standards of connections through density, connectivity, stability and ties variables (Lillbacka, 2006).

\subsection{Performance Measurement (PM) Systems}

PM itself is perceived as one of the most critical and complicated functions in strategic management (Asiaei et al, 2018). According to Simons (1995) argued that PM is tracking the execution of corporate strategy through contrasting actual results with strategic targets. For purpose of this study, the use of the PM should be balanced in diagnostic and interactive style. The basic premise of Simons (1995) suggested that balancing the forces of the various type of control levers such as diagnostic and interactive control could support the control of business strategy. The premise of balance is considered as the core concept in levels of control (LOC), but it is unclear. To get a more conclusive insight into the concept of balance, further examination is required to clarify how a balanced use of LOC creates complementary leading to dynamic tensions and how that tensions makes the better organizational performance. According to scholars, companies require a balance between unlimited opportunities and limited managerial capacity, between self-interest seeking and the desire to contribute, between innovation and predictable goal achievement. For the goal of managing those trade-offs, researchers argue that firms must balance different LOC to generate a proper dynamic tension. Th s may offer an effective synthesis of compliant behavior and creative 
search efforts ensure corporate success. (Asiaei et al, 2018). Moreover, according to the literature of the conflict, tension would properly be advantageous to entities and is not inevitably adverse (Asiaei et al, 2018). Although conflict and tension are characterized as being disruptive and averse, there is ample empirical evidence from the conflict literature which advocates the notion that tension may be positive either individual or firm performance. A good balance use of PM system fosters dialogue, encourage innovation, and focuses organizational attention within the company (Asiaei et al, 2018) which seems to be the more appropriate control system style non-manufacturing firms (Asiaei et al, 2018).

\subsection{Hypotheses Developments}

The balance use of PM systems can play an important role in managing a business organization and through this, motivating strategic intellectual capital dimensions provide vital information for executives. With the forgoing argument, it appears that there is presence of complementarities between the balance use of the PM systems and IC. From the theoretical vantage point, the core notion of the "fit as mediation" of contingency view (Serenko \& Bontis, 2013) states that intangible or knowledge resources have influence on determining the usage and design of PM systems. Accordingly, this study seeks to examine how IC contribute through the mediating impact of the balanced use of PM system. Moreover, it is argued that PM systems from two opposites, but complementary perspectives simultaneously could provide a more systematic and robust PM system (Asiaei et al, 2018). In general, a good balanced use of PM systems in diagnostic and interactive mode produces countervailing positive forces which in turn promote organizational dialogue, creativity, the quality of decision and product development (Koufteros, X et al, 2014.). In general, the hypotheses are proposed as the followings:

Hla: The higher level of human capital, the higher is the balanced use of the diagnostic and interactive PM system

H1b: The higher level of organizational capital, the higher is the balanced use of the diagnostic and interactive PM system

H1c: The higher level of social capital, the higher is the balance use of the diagnostic and interactive PM system

The previous studies having investigating the balance use of PM systems indicated a signification correlation between the design of the use of PM systems and organizational performance (Koufteros, $\mathrm{X}$ et al, 2014). It has been contended that a balance use of PM system has positive influence on firm's performance (Kadak, T. and Laitinen, E.K., 2016). From resource-based view, Henry (2006) asserts that an effective integration between diagnostic and interactive use of PM systems could be regarded as a capacity. Capacity to achieve a balance between countervailing uses of PM systems which inspire creativity and innovativeness labeled as valuable, distinctive, and imperfectly imitable (Asiaei, K. and Jusoh, R. ,2017). In general, it has been asserted that the levers of PM system stimulate positive and negative forces jointly generate a dynamic tension between innovation on the 
one hand and goal achievement on the other, both of which need to be managed to secure the organization's long-term success (Asiaei, K. and Jusoh, R. , 2017). The forgoing argument provides the foundation for following hypothesis:

H2: The higher the balance use of diagnostic and interactive PM systems, the greater is organizational performance.

The previous findings suggest that the advantages attributed to IC may have indirect positive influence on organizational firm through PM systems (Nimtrakoon, 2015; Chen et al, 2005). From this vantage point, it is assumed that knowledge resource such as IC may not be valuable unless it is effectively captured, measured, and managed through employing appropriate PM systems (Wang and Chang, 2005; Chen et al, 2005), According to Widener (2006) once organizations acquire their strategic resources or capabilities, such as IC, the balance use of the PM systems would assist in capturing, measuring and managing those crucial strategic resource effectively, which in turn leads to performance improvement. It is expected that knowledge-based organizations with a high level of IC will put emphasis on more innovative PM systems in this study. In turn, PM systems characterized by diagnostic and interactive PM systems are likely to be associated with enhanced organization performance because such techniques are less narrowly focused and enable managers to focus on the strategic components of organizational performance.

It is hypothesized that firms evaluate their potential in terms of fundamental critical resources and capabilities and then deploy appropriate PM systems which are aligned with those resources which in turn bring about performance improvement (Asiaei et al, 2018). This is how the premise of "fit as mediation" comes into play in this paper. With all the foregoing discussions the following hypothesis is proposed:

H3a: The balanced use of PM system mediates the relationship between human capital and organizational performance.

H3b: The balanced use of PM system mediates the relationship between organizational capital and organizational performance.

H3c: The balanced use of PM system mediates the relationship between social capital and organizational performance.

\section{Methodology}

\subsection{Research Model}

Drawing upon literature reviews and hypothesis development, we propose the research model in below to test all direct, indirect relationship interrelationships among human, organizational, social capital, PM system, and firm performance. 


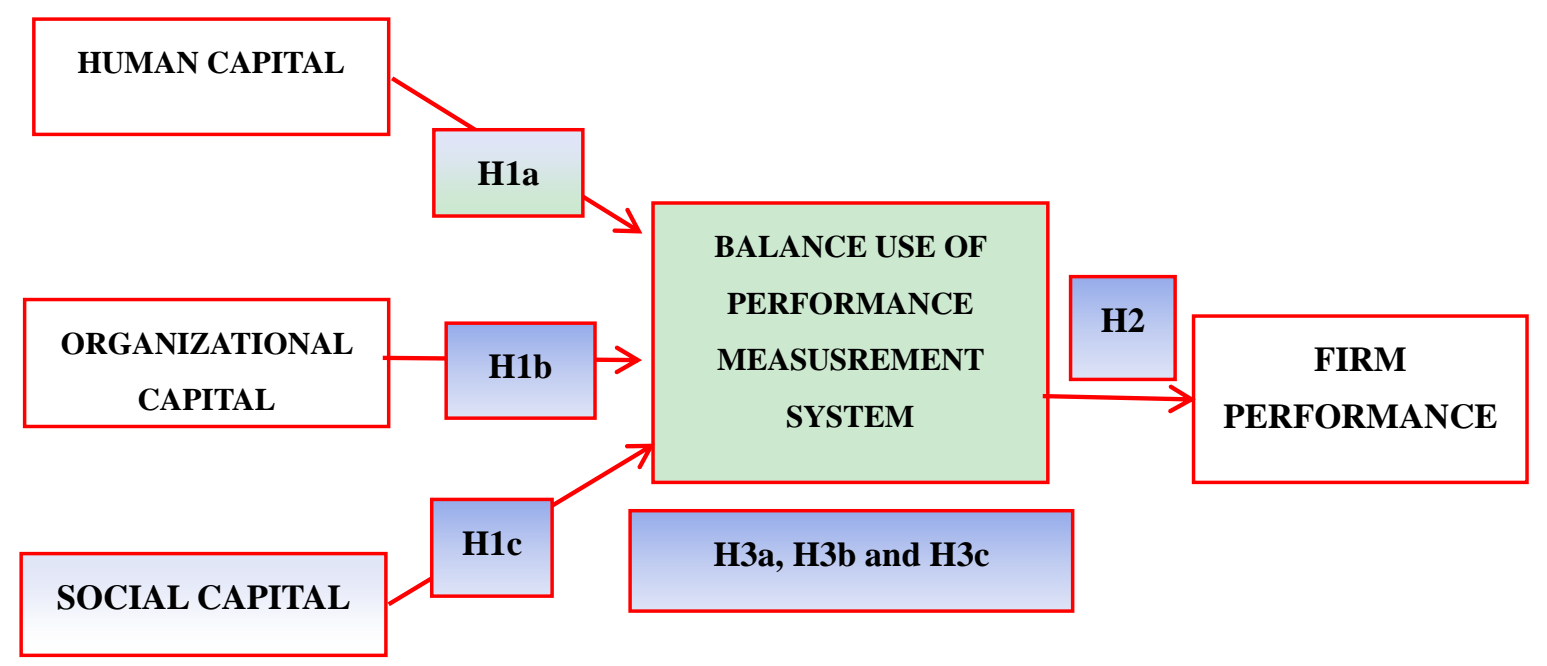

Figure 1. Conceptual model

\subsection{Sample Size}

In academic studies, it would be impossible to collect data from every participant in the population because of limited time, cost and human resource. The list of firms is obtained from the website: www.vietask.com. Determining the sample size depends on the proportion of the total sample variation in the dependent variable. The acceptable sample size should be larger than 30 and smaller than 500 is appropriate for quantitative studies and the required minimum sample size for factor analysis is at least ten times the largest number of the construct used to measure a construct or ten times the largest number of structural paths directed at a particular construct in the structural model ( Creswell J.W., 2009).

The ten times rule of thumb provides only a rough estimate of the minimum sample size requirement. Apply this rule without conducting a power analysis will likely generate low power of hypothesis testing. The sample size recommendation to detect $\mathrm{R}$ squared for $\mathrm{a}$ statistical power of $80 \%$, assuming that it is the widely used level of statistical power. The sample size requirement for detecting the minimum $\mathrm{R}$ squared value of 0.5 follows these criteria (Hair et al., 2010) : (1) Significance level of 5\%. (2) A maximum number of arrows pointing at a construct and (3) Measurement models with loading above the common threshold of 0.7 . For my dissertation, basing on www.vietask.com, I identified there are total of 714,000 firms in 64 provinces in Vietnam and I select randomly 448 firms for survey.

\subsection{Measurement of Constructs}

\subsubsection{Independent Variables (Human, Organizational and Social Capital)}

The measurement items of the three dimensions of IC, organizational and social capital, were mainly derived from measurement scales developed by Subramanian and Youndt (2005). The measurement items of human capital construct reflect "overall skills, experiences and education background of the firm's employees. The measurement items of the organizational 
capital reflect the firm's ability to reserve the knowledge in physical repositories such as information system, manuals, and patents as well as process and corporate culture. Social capital measures “an organization's overall ability to share and leverage knowledge among a social network of employees, customers, suppliers and alliance partners.

\subsubsection{Dependent variable (Firm performance)}

This study has considered the view that employing multiple indicators enables assessment of a more complex and informative performance measure (Subramaniam, M., \& Youndt, M. A., 2005). Respondents were asked questions to compare the firm developments in the current year with the previous year.

\subsubsection{Mediator (The balance use of Performance Measurement)}

As mentioned earlier, Simons (1995) specifies two countervailing types of the use of control systems, namely diagnostic and interactive. The former is defined as the formal feedback systems employed for monitoring predictable objective attainment whereas the latter focuses attention and fosters dialogue and learning throughout the entity through providing signals sent by high level administrators. In this respect, this study took the instrument used by Henri (2006) which was originally adopted from Vandenbosch (1999) in order to measure interactive and diagnostic uses of PM systems. The Vandenbosch (1999) instrument had been developed initially for the purpose of measuring the use of executive support systems. The measurement constituted by a set of dimensions which mainly includes score keeping (diagnostic) and attention- focusing (interactive). This instrument had been developed relying on theories of accounting control prior to its adaptation to a management information setting. This is the rationale behind the preference for the forgoing measurement tool. This instrument consists of eleven items across the two broad dimensions, namely interactive PMS use and diagnostic PMS use.

\subsection{Testing Tools}

This study uses two software programs to analyze the data collected. Descriptive statistics, reliability testing and exploratory factor analysis (EFA) are performance using Statistical Package for Social Science (SPSS) software. Next, Confirmatory factor analysis (CFA) and Structural equation modeling (SEM) conducted afterward to estimate an overall research model are performed by Partial least squared (PLS) software. Hulland (1999) argue that PLS

maximize the explanatory power of conceptual or research model by examining $R^{2}$ values for

the dependent (endogenous) constants and can model structural relations among latent variables and relationships between latent variables and manifest indicators. Moreover, PLS has been adopted in present study because it is more appropriate for examining complex models and it imposes minimal constraints in terms of measurement scales, sample size and residual distribution (Hulland, 1999). 


\section{The Result}

\subsection{The Result of the Construct Reliability and Validity Evaluation}

At first, we use Cronbach alpha $(\boldsymbol{\alpha})$ for reliability analysis in order to measure the internal consistency of the measurement scales. The acceptable value of $\boldsymbol{\alpha}$ should be above 0.6 (Hair et al., 2010). Next, we use exploratory factor analysis (EFA) technique to conduct dimensionality analysis indicated by the factor loading score. The general purpose of factor analytic techniques is to condense the information contained in the original construct into a smaller set of new composite dimensions or factors.

The test result indicates that all factor loading scores qualified a suggested level of 0.5 results in the satisfaction of the condition of uni-dimensionality confirmation (Hair et al., 2010). In our study, with an original set of 45 measurement items, there were only 26 items which qualified the factor loading score threshold of 0.5 with a minimum score of 0.575 .

\subsection{The Result of Convergent and Discriminant Validity Evaluation}

Confirmatory factor analysis (CFA) was conducted to assess how the conceptual model fit data with the help of PLS software. Regarding overall model fitness, to make sure data fit to model well, root mean square error of approximation (RMSEA) should be smaller than or equal to 0.083, Goodness-of-fit index (GFI), and Comparative fit index (CFI) should satisfy thresholds of 0.91. Our test resulted acceptable fit for data set (GFI $=0.801, \mathrm{CFI}=0.845$ and RMSEA = 0.104). Furtherly, we use CFA technique to test convergent and discriminant validity. I checked all average variance extracted (AVEs) and composite reliabilities (CRs). All AVEs are higher the suggested level of 0.5 and CRs are also above the proposed level of 0.7. Therefore, convergent validity is satisfied. For the test of the discriminant validity, if the square root AVE of each construct is larger than the correlation coefficient of that construct compared with any other construct in the model, constructs indeed are different from one another (Hair et al., 2010). The test result demonstrates that all constructs carry enough discriminant validity.

\subsection{Direct Effects}

Table 1. First Regression Analysis

\begin{tabular}{l|l|l|l|l|l}
\hline No & Hypothesis & Path & $\begin{array}{l}\text { Parameter } \\
\text { estimiate }(\beta)\end{array}$ & SE & t-statistic \\
\hline 1 & H1a & HC=> the balance use PM & 0.0397 & 0.1132 & 3.452 \\
\hline 2 & H1b & OC=> the balance use PM & 0.0215 & 0.1063 & 2.452 \\
\hline 3 & H1c & $\begin{array}{l}\text { SC=> the balance use of } \\
\text { PM }\end{array}$ & 0.013 & 0.0948 & 1.729 \\
\hline 4 & H2 & the balance use PM=>FP & 0.0212 & 0.085 & 2.3873 \\
\hline
\end{tabular}


$\beta<0.05=>$ statistically significant

The PLS estimates of the structural model are reported in Table 1 which include standardized path coefficients $(\beta)$. The results of the PLS estimation show that There are positive significant relationships between the level of $\mathrm{HC}, \mathrm{OC}$ and SC and the balance use of PM. Therefore, H1a and $\mathrm{H} 1 \mathrm{~b}$ are supported. Similarly, the balance of PM system has positive significant relationships between the level of $\mathrm{HC}, \mathrm{OC}$ and SC and the balance use of PM, and

H1a,1b and 1c are supported. Similarly, the balance use of PM system has positive significant relationship with FP. Therefore, $\mathrm{H} 2$ is supported.

\subsection{Indirect Effects}

Table 2. Mediation Analysis

\begin{tabular}{l|l|l|l|l}
\hline Indirect effect- hypothesis & $\begin{array}{l}\text { Mean } \\
(\mathrm{axb})\end{array}$ & $\begin{array}{l}\text { Lower bound of } \\
\text { confidence } \\
\text { interval }\end{array}$ & $\begin{array}{l}\text { Upper bound } \\
\text { of confident } \\
\text { interval }\end{array}$ & $\begin{array}{l}\text { Type of } \\
\text { mediation }\end{array}$ \\
\hline $\begin{array}{l}\text { H3a: HC=> the balance use of } \\
\text { MP=> FP }\end{array}$ & 0.0082 & 0.0949 & 0.0993 & Partial \\
\hline $\begin{array}{l}\text { H3b: OC }=>\text { the balance use of } \\
\text { MP }=>\text { FP }\end{array}$ & 0.00527 & 0.0513 & 0.0542 & Partial \\
$\begin{array}{l}\text { H3c: SC }=>\text { the balance use of } \\
\text { MP }=>\text { FP }\end{array}$ & 0.00980 & 0.0938 & 0.0972 & Partial \\
\hline
\end{tabular}

According Zhao et al. (2010), Maximum evidence for mediation, also called full mediation, would occur if inclusion of the mediation variable drops the direct relationship between the independent variable and dependent variable (see pathway $c$ in diagram above) to zero. This rarely, if ever, occurs. The most likely event is that $c$ becomes a weaker, yet still significant path with the inclusion of the mediation effect. Meanwhile, Partial mediation maintains that the mediating variable accounts for some, but not all, of the relationship between the independent variable and dependent variable. Partial mediation implies that there is not only a significant relationship between the mediator and the dependent variable, but also some direct relationship between the independent and dependent variable is an illustration of a mediator model. Based on foregoing discussion, the recommended 5000 bootstrap samples were performed in order to test the mediating effects in this study. Overall, the results reveal that 95 percent bootstrap confidence intervals for the total effects and those of balance use of PM system (mediating variable in this study) are positive and do not include zero. The result of mediation models is comprehensively present in table 2 in above.

As presented in Table 2, bootstrapping the model (Figure 2) with the balance use of PM system as mediating resulted in 95 percent confidence interval $(0.0949,0.0993)$ for indirect effect of HC on FP. This confident interval does not include zero, so, the indirect effect a1xb1 
(0.0082) is significant and mediation through the balance use of PM system is established (H3a is supported). In addition, the direct influence of the HC c (0.0247) on FP is also significant, so, the mediation type is partial mediation. Next, the same approach was performed to test the mediating effect of balance use of PM system on the relationship between OC and FP. The result shows a 95 percent confident interval $(0.0513,0.0542)$ for indirect impact of OC on FP. This confident interval also does not include zero, so, the indirect effect a $2 \mathrm{xb} 2(0.00527)$ is significant, so, H3b is supported. The direct impact of OC on FP is significant c (0.00257), so, the type of mediation is partial mediation. In same vein, the procedure of bootstrapping for exploring the indirect effect of SC on FP through the balance use of PM system shows a 95 percent confident interval $(0.0938,0.0972)$. This confident interval does not include zero, so the indirect effect a3xb3 (0.00980) is significant, so, the mediation through the balance use of PM system is confirmed. The direct effect $\mathrm{c}$ (0.0029) is significant as well. Accordingly, the partial mediation is established.

\section{Discussion and Conclusion}

Although the effect of IC on firm performance has been studied substantially studied. Less effort has been devoted to understanding the balance use of PM systems in leveraging organization's most asset. It is argued that FP is influenced by the appropriate measurement and management of the underlying critical success factors. This paper provides empirical evidence that the level of $\mathrm{HC}$, OC and SC are related to the use of PM systems in a balanced diagnostic and interactive style. Furthermore, this balanced use of PM system mediates the impacts of HC, OC and SC on FP. As expected, firms that have higher levels of IC dimensions would achieve significantly superior performance when they put more value on the balance use of PM systems.

The first three hypotheses investigate whether $\mathrm{HC}$, OC and SC effect significantly on the balance use of PM systems.

The second hypothesis examines whether the balance use of PM systems is positively associated with FP. This indicate that companies which employ the balanced use of diagnostic and interactive PM systems to a greater extent tend to achieve superior FP. This result is consistent with conflict literature which tension is not inevitably adverse in essence but alternatively might be favorable to entities (De Dreu, 1997). It is said that despite some notions which assume that conflict and tension literature is adverse and destructive, ample evidence within conflict literature asserts that they are likely advantageous to FP.

The final set of hypotheses examine the mediating role of the balance use of PM systems on the relationships between $\mathrm{HC}, \mathrm{OC}$ and $\mathrm{SC}$, and $\mathrm{FP}$. H3a, $\mathrm{H} 3 \mathrm{~b}$ and $\mathrm{H} 3 \mathrm{c}$ are hypothesized based on the premise that organizations tend to utilize the appropriate PMS that is aligned with their capabilities in order to manage those resource more effectively, thereby enjoying more desired FP.

The findings show that some of the advantages stem from IC dimensions would affect FP indirectly through the emphasis put on the usage of PM systems. The findings are also 
consistent with resource-based view of the firm which assumes that firms are not able to realize their if IC dimensions are not managed properly. According to Simon et al (2000), PM systems are perceived as a powerful lever to support management of strategic resources. In this regard, managers might to employ appropriate PM systems that offer relevant information concerning the firm's underlying IC dimensions that are perceived as critical success factors.

\subsection{Academic and Practical Implications}

The results of this paper suggest some theoretical and practical implications. While the effects of $\mathrm{HC}, \mathrm{OC}$ and SC on FP have received considerable attention, very few literatures are known about the important role of management control systems, especially, the PM systems, in facilitating the strategic resources such as IC dimensions. In this regard, this study contributes to academia by providing empirical evidences on the importance of the balance use of diagnostic and interactive PM systems in supporting and leveraging the firm's strategic resources.

This study contributes to the extant body of research at the boundary between IC dimensions and FP. It synthesizes a robust framework from the contingency lens, resource-based view and management literatures. This theoretical model offers fascinating insights about the dual roles of IC either in making a breakthrough in the evolution of organizational control systems or predicting FP.

This study also offers further insights into whether the emphasis put on the use of PMS, from two individual but complementary aspects to the organization through examining the relationship with FP.

For practical implication, the findings are pivotal to management in designing relevant PM systems that exploit intangible assets. The findings provide insights into the way practitioners adopt appropriate types of PM systems, which are aligned with the level of IC on FP and managers are encouraged to have balance use of diagnostic and interactive PM systems.

\subsection{Limitation and Further Researches}

This study also has limitation. The findings are based largely perceived opinions of key informants. Such perceptions are likely to be insufficient in understanding the full extent of latent construct. Although the development of validated instruments and the pre-tests on survey experts and key executive could alleviate this issue. Moreover, the institutional differences in various types of organizations could explain some of the findings in the current study since the paper is based on a cross-sectional survey of all publicly listed companies instead of one particular type of organization or industry. Further studies may carry out a series of in-depth case studies to explore exactly how different types of organizational control systems could illuminate IC at an organizational level.

Furthermore, the use of quantitative study approach is not able to provide answers as to "why" and "how" certain linkages work or mechanisms cause certain things. Future studies may carry out a qualitative study approach through interviews or in-depth case studies to 
better understand the context and environment of a company that provide details about human behavior, emotion, and personality characteristics relating to IC and PM system.

Further research may also consider a longitudinal examination of the causality and interrelationships among factors that are pivotal to IC and PM system development among factors that are pivotal to IC and PM system development. Finally, in undertaking studies examining the role of management control systems in knowledge-intensive organizations, scholars may consider the recent warning highlighted by Leif Edvinsson (2013, p. 169), when he commented that, "we need to go beyond IC reporting, to think in terms of cross-disciplinary systematized perspectives that will increase the IC consciousness."

\section{References}

Asiaei, K., \& Jusoh, R. (2017). Using a robust performance measurement system to illuminate intellectual capital. International Journal of Accounting Information Systems, 26, 1-19. https://doi.org/10.1016/j.accinf.2017.06.003

Asiaei, K., Jusoh, R., \& Bontis, N. (2018). Intellectual capital and performance measurement systems in Iran. Journal of Intellectual Capital, 19(2), 294-320. https://doi.org/10.1108/JIC-11-2016-0125

Bontis, N., Ciambotti, M., Palazzi, F., \& Sgro, F. (2018). Intellectual capital and financial performance in social cooperative enterprises. Journal of Intellectual Capital, 19(4), 712-731. https://doi.org/10.1108/JIC-03-2017-0049

Chen, M. C., Cheng, S. J., and Hwang, Y. (2005). An empirical investigation of the relationship between intellectual capital and firms' market value and financial performance. Journal of Intellectual Capital, 6(2), 159-176. https://doi.org/10.1108/14691930510592771

Cleary, P. (2015). An empirical investigation of the impact of management accounting on structural capital and business performance. Journal of Intellectual Capital, 16(3), 566-586. https://doi.org/10.1108/JIC-10-2014-0114

Creswell, J. W. (2009). Mapping the field of mixed methods research.

Cuozzo, B., Dumay, J., Palmaccio, M., \& Lombardi, R. (2017). Intellectual capital disclosure: a structured literature review. Journal of Intellectual Capital, 18(1), 9-28. https://doi.org/10.1108/JIC-10-2016-0104

Davison, J. (2014). Visual rhetoric and the case of intellectual capital. Accounting, Organizations and Society, 39(1), 20-37. https://doi.org/10.1016/j.aos.2014.01.001

Edvinsson, L. (2013). IC 21: reflections from 21 years of IC practice and theory. Journal of Intellectual Capital, 14(1), 163-172. https://doi.org/10.1108/14691931311289075

Felício, J. A., Couto, E., \& Caiado, J. (2014). Human capital, social capital and organizational performance. Management Decision. https://doi.org/10.1108/MD-04-2013-0260

Guilding, C., Cravens, K. S., \& Tayles, M. (2000). An international comparison of strategic management accounting practices. Management Accounting Research, 11(1), 113-135. 
https://doi.org/10.1006/mare.1999.0120

Hair, J. F., Black. W. C., Babin., B. J., Anderson, R. E. (2010) Multivariate data analysis, a global perspective. New Jersey. Pearson. Ed, 7, 816.

Henri, J. F. (2006). Organizational culture and performance measurement systems. Accounting, organizations and society, 31(1), 77-103. https://doi.org/10.1016/j.aos.2004.10.003

Hulland, J. (1999). Use of partial least squares (PLS) in strategic management research: A review of four recent studies. Strategic management journal, 20(2), 195-204. https://doi.org/10.1002/(SICI)1097-0266(199902)20:2<195::AID-SMJ13>3.0.CO;2-7

Kadak, T., and Laitinen, E. K. (2016). "What matters with PMS? Critical check points in the success of PMS", in Farrell, A.M. (Ed.), Performance Measurement and Management Control: Contemporary Issues, Emerald Group Publishing Limited, Bingley, pp. 111-140. https://doi.org/10.1108/S1479-351220160000031004

Koufteros, X., Verghese, A. J., \& Lucianetti, L. (2014). The effect of performance measurement systems on firm performance: a cross-sectional and a longitudinal study. Journal of Operations Management, 32(6), 313-336.

https://doi.org/10.1016/j.jom.2014.06.003

Lev, B., \& Zambon, S. (2003). Intangibles and intellectual capital: an introduction to a special issue. European Accounting Review, 12(4), 597-603.

https://doi.org/10.1080/0963818032000162849

Lillbacka, R. (2006). Measuring Social Capital. Acta Sociologica.

https://doi.org/10.1177/0001699306064774

Mention, A. L., \& Bontis, N. (2013). Intellectual capital and performance within the banking banking sector of Luxembourg and Belgium. Journal of Intellectual capital. Journal of Intellectual Capital, 14(2), 286-309. https://doi.org/10.1108/14691931311323896

Nhon, H. T., Thong, B. Q., \& Van Phuong, N. (2018). The Impact of Intellectual Capital Dimensions on Vietnamese Information Communication Technology Firm Performance: A Mediation Analysis of Human and Social Capital. Academy of Strategic Management Journal, 17(1), 1-15.

Nimtrakoon, S. (2015). The relationship between intellectual capital, firms' market value and financial performance: empirical evidence from the ASEAN. Journal of Intellectual Capital, 16(3), 587-618. https://doi.org/10.1108/JIC-09-2014-0104

Novas, J. C., \& Jordão, R. V. D. (2017). Knowledge management and intellectual capital in networks of small-and medium-sized enterprises. Journal of Intellectual Capital, 18(3), 667-692. https://doi.org/10.1108/JIC-11-2016-0120

Serenko, \& Bontis, N. (2013). Global ranking of knowledge management and intellectual capital academic journals: 2013 update. Journal of Knowledge Management, 17(2), 307-326. https://doi.org/10.1108/13673271311315231

Simons, R. (1995). Levers of Control: How Managers Use Innovative Control Systems to 
Drive Strategic Renewal, Harvard University Press, Boston, MA.

Subramaniam, M., \& Youndt, M. A. (2005). The influence of intellectual capital on the types of innovative capabilities. Academy of Management journal, 48(3), 450-463. https://doi.org/10.5465/amj.2005.17407911

Tayles, M., Pike, R. H., \& Sofian, S. (2007). Intellectual capital, management accounting practices and corporate performance: perceptions of managers. Accounting, Auditing \& Accountability Journal, 20(4), 522-548. https://doi.org/10.1108/09513570710762575

Tong, C., Tak, W. I. W., \& Wong, A. (2015). The Impact of knowledge sharing on the relationship between organizational culture and Job satisfaction: The perception information communication and technology (ICT) practitioners in Hong Kong. International Journal of Human Resource Studies, 5(1), 19. https://doi.org/10.5296/ijhrs.v5i1.6895

Toorchi, M., Asiaei, K., \& Dehghan, M. (2015). Intellectual capital and management accounting practices: evidence from Iran. Procedia Economics and Finance, 31, 775-788. https://doi.org/10.1016/S2212-5671(15)01167-3

Van Den Bosch, F. A., Volberda, H. W., \& De Boer, M. (1999). Coevolution of firm absorptive capacity and knowledge environment: Organizational forms and combinative capabilities. Organization science, 10(5), 551-568. https://doi.org/10.1287/orsc.10.5.551

Vuong, Q. H., Napier, N. K., Vu, H., Nguyen, M. C., \& Tran, T. D. (2014). Measuring corporate innovation capacity: Experience and implications from i2Metrix implementation in Vietnam, in SSRN.

Wang, W. Y., \& Chang, C. (2005). Intellectual capital and performance in causal models: Evidence from the information technology industry in Taiwan. Journal of intellectual capital, 6(2), 222-236. https://doi.org/10.1108/14691930510592816

Whiteley, P. F. (2015). Social Capital. In International Encyclopedia of the Social \& Behavioral Sciences: Second Edition. https://doi.org/10.1016/B978-0-08-097086-8.93127-1

Widener, S. K. (2006). Associations between strategic resource importance and performance measure use: The impact on firm performance. Management Accounting Research, 17(4), 433-457. https://doi.org/10.1016/j.mar.2005.10.002

Youndt, M. A., Subramaniam, M., \& Snell, S. A. (2004). Intellectual capital profiles: An examination of investments and returns. Journal of Management studies, 41(2), 335-361. https://doi.org/10.1111/j.1467-6486.2004.00435.x

\section{Copyright}

Copyright for this article is retained by the author(s), with first publication rights granted to the journal.

This is an open-access article distributed under the terms and conditions of the Creative Commons Attribution license (http://creativecommons.org/licenses/by/4.0/). 